NASA Technical Memorandum 103095

\title{
Fatigue Crack Growth in a Unidirectional SCS-6/Ti-15-3 Composite
}

Peter Kantzos and Jack Telesman

National Aeronautics and Space Administration

Lewis Research Center

Cleveland, Ohio

Louis Ghosn

Sverdrup Technology, Inc.

NASA Lewis Research Center Group

Cleveland, Ohio

Prepared for the

Third Symposium on Composite Materials: Fatigue and Fracture sponsored by the American Society for Testing Materials

Orlando, Florida, November 6-9, 1989 
FATIGUE CRACK GROWTH IN A UNIDIRECTIONAL SCS-6/Ti-15-3 COMPOSITE

\author{
Peter Kantzos and Jack Telesman \\ National Aeronautics and Space Administration \\ Lewis Research Center \\ Cleveland, Ohio 44135 \\ Louis Ghosn \\ Sverdrup Technology, Inc. \\ NASA Lewis Research Center Group \\ Cleveland, Ohio 44135
}

Abstract

An investigation was conducted to characterize and model the fatigue crack growth (FCG) behavior of a SCS-6/Ti-15-3 metal matrix composite. Part of the study was conducted using a fatigue loading stage mounted inside a scanning electron microscope (SEM). This unique facility allowed high magnification viewing of the composite fatigue processes and measurement of the near crack tip displacements. The unidirectional composite was tested in the $[0]_{8}$ (i.e longitudinal) and $[90]_{8}$ (i.e. transverse) orientations. For comparison purposes unreinforced matrix material produced by the identical process as the reinforced material was also tested.

The results of the study reveal that the fatigue crack growth behavior of the composite is a function of specimen geometry, fiber orientation and the interaction of local stress fields with the highly anisotropic composite. In the case of [0] $]_{8}$ oriented single edge notch (SEN) specimens and [90] oriented compact tension (CT) specimens, the crack growth was normal to the loading direction. However, for the $[0]_{8}$ CT specimens the crack grew mostly parallel to the loading and the fiber direction.

The unusual fatigue behavior of the $[0]_{8}$ CT specimens was attributed to the specimen geometry and the associated high tensile 
bending stresses perpendicular to the fiber direction. These stresses resulted in preferential cracking in the weak interface region perpendicular to the fiber direction. The interface region, and in particular the carbon coating surrounding the fiber proved to be the composites weakest link.

In the $[0]_{8}$ SEN the crack growth was confined to the matrix leaving behind unbroken fibers which bridged the cracked surfaces. As the crack grew longer, more fibers bridged the crack resulting in a progressive decrease in the crack growth rates and eventual crack arrest. The actual near crack tip displacement measurements were used in a proposed formulation for a bridging-corrected effective crack driving force, $\Delta \mathrm{K}_{\text {eff }}$. This parameter was able to account for most of the experienced bridging and correlated the $[0]_{8}$ SEN fatigue crack growth data reasonably well.

Key Words: Metal Matrix Composite, Fatigue Crack Growth, Crack Bridging, Fatigue Mechanisms.

Introduction

The new generation of aerospace vehicles will require materials capable of withstanding high temperatures while retaining a high stiffness under relatively high loads. Continuous fiber, metal matrix composites (MMC) are candidate materials for such applications. One of these candidate materials is a Ti-15V-3Cr3Al-3Sn matrix reinforced by continuous SiC fibers. Before these 
materials become widely utilized in aerospace applications, their fatigue behavior have to be understood and reliable life prediction methodology has to be developed.

Relatively little information is available concerning the fatigue behavior of continuous fiber reinforced composites. The objective of this study is to broaden this knowledge by investigating in detail the fatigue behavior of the above mentioned composite system. The emphasis of the study was twofold: 1) identification of the fatigue crack initiation and propagation damage processes with special attention focused on identifying the composite constituent most susceptible to fatigue damage; and 2) identification of the appropriate crack driving force for this composite. To achieve these goals, part of the study was conducted using a fatigue loading stage mounted inside an SEM. This unique facility, developed at NASA Lewis (1), allows real-time dynamic and static viewing of the fatigue crack initiation and crack propagation processes.

Material

The composite used in this study is a Ti-15V-3Cr-3Al-3Sn ( Ti15-3) alloy matrix reinforced by $145 \mu \mathrm{m}$ average diameter, continuous SiC (SCS-6) fibers. All the composite specimens used in this study were obtained from a single, eight ply, unidirectionally reinforced panel manufactured by Textron Specialty Materials Division. The panel size was $30 \times 30 \times 0.21 \mathrm{~cm}$. Specimens were also machined out of a $30 \times 30 \times 1 \mathrm{~cm}$ panel of unreinforced matrix, using the same Ti-15-3 matrix foil and same consolidation techniques 
employed in composite production.

The matrix is a metastable beta phase alloy, chosen because it can be cold rolled to very thin sheets. This enables a more cost effective processing of the composite. Sample micrographs of the reinforced composite are shown in Fig 1 . The SiC fiber is surrounded by a complex multilayer structure (Fig 1b) which consists mainly of a multilayer carbon coating approximately $3 \mu \mathrm{m}$ thick and an approximately 0.5-1 $\mu$ m thick reaction zone consisting mainly of brittle intermetallic phases (2). The combination of the carbon layers and the reaction zone will henceforth be referred to as the interface region.

Heat Treatment

Specimens were tested both in the as-received and heat treated condition. The heat treatment consisted of 24 hours at $700 \mathrm{C}$ in vacuum. The purpose of the heat treatment was to precipitate out the alpha phase. The heat treatment did not produce any additional noticeable fiber/matrix interactions and the reaction zone remained unchanged (3).

Mechanical Testing

Fatigue crack growth (FCG) testing was performed using single edge notch (SEN) and compact tension (CT) specimens. The SEN specimens were tested in the $[0]_{8}$ orientation only. The CT composite specimens were tested in two orientations: 1) longitudinal, $[0]_{8}$, with fibers oriented parallel to the loading direction; and 2) transverse, $[90]_{8}$, with fibers perpendicular to the loading direction. Unreinforced matrix specimens were also 
tested using CT specimens.

All machining was done using diamond tip tools. Prior to testing, all specimens were polished to enhance crack detection.

The test matrix is shown in Table I. The SEN specimens were tested in the fatigue loading stage mounted inside an SEM. The testing was conducted at room temperature at a load ratio $\mathrm{R}$ of 0.1 with the maximum load being $2.24 \mathrm{KN}$. Test frequency was $5 \mathrm{~Hz}$ with frequent holds at varied loads to observe the fatigue processes and measure near crack tip displacements. An extensometer was mounted in the crack mouth of the specimen to determine the changes in the compliance. The vacuum inside the SEM was approximately $1 \times 10^{-6}$ torr. Testing of the CT specimens was performed at room temperature and ambient environment using a computer controlled, closed loop, servo-hydraulic machine. The tests were performed using constant load range per each test at a frequency of $5 \mathrm{~Hz}$ and load ratios $\mathrm{R}$ of 0.5 and 0.1 . A computerized data acquisition system was used to determine the crack length by measuring the specimen compliance through an extensometer mounted in the crack mouth of the specimen. Data was also gathered through periodical optical readings to ensure accurate results.

Post-Failure Analysis

Following each test, extensive metallography and fractography was performed in order to evaluate fatigue failure processes. Each sample fracture surface was examined in the scanning electron microscope, with some samples also being sectioned to determine the extent of damage. 
Results

SEN Specimens, $[0]_{8}$ Orientation

The crack growth behavior of the $[0]_{8}$ SEN specimens tested in the insitu loading stage resulted in the crack growing primarily in the direction normal to the applied load. The crack length versus cycles plot (Fig 2) reveals a progressive decrease in the fatigue crack growth rate with an increase in the crack length followed by an eventual crack arrest.

The high magnification observations of the fatigue processes revealed that crack initiation occurred in the first few cycles. The initiation occurred by a failure of the partly machined fibers at the notch tip (Fig 3). The crack front subsequently propagated into the matrix ligament. Crack propagation in the matrix was always associated with formation of slip bands in the cyclic plastic zone ahead of the crack tip. The stable fatigue crack growth was mainly confined to the matrix leaving in its wake unbroken SCS-6 fibers to bridge the two cracked surfaces.

A sequence of high magnification micrographs revealing the crack growth process observed for the SEN specimens is shown in Fig 4. As shown in the first micrograph in the sequence (Fig 4 a) the main crack front has already approached a fiber and has started to grow around it. The reappearance of the crack front from behind the fiber to the outer specimen surface was preceded by the formation of slip bands (Fig 4a). As the crack front approached the outer surface, the slip bands became more pronounced (Fig 4b). A few thousand cycles later, the leading segments of the crack front 
broke through the outer surface (Fig 4c). These crack segments were visible at maximum load (Fig 4c), however as the load was released the crack segments closed making it impossible to detect the crack tip region, even at high magnifications (Fig 4d). After further crack growth in the matrix ligament (Fig 4e) the entire ligament failed leaving in its wake unbroken fibers to bridge the crack. Once the entire matrix ligament between the two fibers was broken, a significant increase in the crack opening displacements (COD) in the matrix ligament occurred due to the residual tensile stresses present in the matrix (Fig 4f). At that point the cracked matrix ligament remained open during the entire loading cycle. The behavior described above continued throughout the test until crack arrest was reached, resulting in four unbroken fiber rows bridging the two cracked surfaces (Fig 5).

In cases where the fibers were partly exposed during the polishing process, some secondary cracking initiated at the fiber/matrix interface ahead of the crack tip. This secondary cracking was confined predominantly to the near surface region in the immediate vicinity of the exposed fiber. There was very little interaction observed between these small surface cracks and the main crack. Overall their effect on the crack growth behavior of the main crack was negligible.

Using high magnification micrographs of the near-crack tip region, crack opening displacements were measured as a function of the applied load and the distance behind the crack tip, $t$. One of the many data sets obtained is shown in Fig 6 . Shown in the figure 
is the measured COD range for a bridged crack as a function of distance behind the crack tip, $\Delta u(t)_{B}$, and analytically derived COD range for an unbridged SEN specimen, $\Delta u_{N B}$, at the same applied stress intensity range, $\Delta \mathrm{K}_{\mathrm{app}}$. The crack opening displacement range, $\Delta u(t)_{\text {तв }}$ for an unbridged SEN specimen was calculated by the use of weight functions (4) as a function of distance behind the crack tip using the following integral equation:

$$
\Delta \mathrm{u}(\mathrm{t})_{\mathrm{NB}}=\frac{1}{\mathrm{E}} \int \mathrm{h}(\mathrm{t}, \pm 0, \mathrm{C}) \Delta \mathrm{K}_{\mathrm{app}} \mathrm{dC}
$$

where $\mathrm{E}$ is the modulus of the composite, $\mathrm{h}$ is the Bueckner weight function, $c$ is the crack length and dc is the incremental crack length. The difference between the measured COD's and the predicted COD's for an unbridged SEN specimen is significant (Fig 6) and can be used to quantify fiber bridging effect as will be shown later on.

The extensometer mounted in the crack mouth of the specimen showed no apparent change in the compliance throughout the entire duration of the test. In comparison, according to the calculations performed, an unbridged SEN specimen would have been expected to experience an almost three-fold increase in the compliance for the amount of crack growth that has taken place.

CT Specimens, $[0]_{8}$ Orientation

In contrast to the SEN specimens, the overall direction of fatigue failure for $[0]_{8}$ oriented CT specimens was parallel to the loading direction and perpendicular to the machined notch, as shown in Fig 7. The FCG data for the $[0]_{8}$ specimens is shown in Fig 8 in 
the form of crack length a vs number of cycles $\mathrm{N}$ (Fig 8a) and crack growth rate da/dN vs a (Fig $8 \mathrm{~b})$. The data was not analyzed in terms of the applied $\Delta \mathrm{K}$ due to the lack of $\mathrm{K}_{\mathrm{I}}$ and $\mathrm{K}_{\mathrm{II}}$ solutions for a crack in a CT specimen growing parallel to the loading direction. The FCG data, shown in Fig 8, does reveal an increase of the FCG rate with an increase in the crack length indicating a probable increase of the crack tip stress field with crack growth.

A fractographic evaluation was performed to reveal the fatigue failure processes which resulted in this rather unusual behavior. The first row of fibers at the machined notch which were partly damaged by the machining process (Fig 9) failed preferentially. The crack front continued for a short distance to grow in the plane of the first fiber row parallel to the loading direction (Fig 7) before turning and growing perpendicular to the loading direction through the matrix ligament. As further seen in Figs 7 and 9, after the crack front reached the undamaged second row of fibers it again started to grow along the loading direction. After the crack reached a critical length, the specimens failed through debonding of the fibers and tearing of the matrix.

The stress field of the main crack resulted in the initiation of number of secondary cracks ahead of the crack tip (Fig 10). As shown in the figure, the cross section of the specimen revealed a multitude of small secondary cracks in various stages of coalescence. Careful examination of the figure showed that the as yet uncoalesced cracks have all initiated in the interface region. Upon further fatigue loading, these small interface cracks 
propagated into the matrix ligaments and joined.

The microcracking appears to have initiated typically in the fiber/matrix interface region. A closer examination revealed a somewhat greater tendency for the cracks to initiate in the carbon coating of the fibers (Fig 11) rather than the reaction zone adjacent to the coating. As shown in Fig 11a, a crack presumably initiated between the carbon coating layers, cracked through the reaction zone and entered the matrix (crack width in the matrix is exaggerated due to the preferential etching of the matrix material adjacent to the crack). Irregardless of the precise crack initiation location, the microcracks usually tended to encompass the carbon coatings as well as the brittle intermetallic reaction zone (i.e. the entire interface region). Post failure analysis revealed carbon coating regions adhering to the matrix after the fiber has broken away, again indicating that cracking must have occurred between the fiber and the coating (Fig 11b). These results support recent findings of Gabb et al. (5) who also identified the carbon coating as a site for preferential crack initiation. Johnson et al. (6) while not differentiating between the carbon layer and the reaction zone, also suggested that the weak interface region is responsible for degradation of fatigue life of this composite.

Post failure fractographic analysis of the CT [0] $]_{8}$ composite revealed that the interface region was not only the site for preferential crack initiation but was also the controlling factor which influenced crack propagation behavior. Throughout the test the crack growth occurred preferentially in the interface region. 
The crack growth process consisted of the continuous cracking of the interface region at or ahead of the crack tip, followed by crack growth into the matrix ligaments and subsequent crack coalescence. This phenomena is illustrated in Fig 12. In particular, note in the fractograph (Fig 12b) of a high da/dN region just prior to final failure, that stable crack growth has occurred in the areas adjacent to the interface. However, the remaining part of the matrix ligament failed through void coalescence during the catastrophic failure. This fractograph clearly shows the direction of localized crack growth to be from the interface region to the matrix ligament.

The crack propagation within the matrix was transgranular in nature (Fig 12). The active fatigue failure mechanisms in the matrix included evidence of striation formation, slip band deformation and some cleavage. Some secondary cracking was present in the matrix foil laminate boundaries perpendicular to the main crack front.

CT Specimens, [90] $]_{8}$ Composite and Unreinforced Matrix Material

Contrary to the behavior of the CT $[0]_{8}$ specimens, for both the $[90]_{8}$ composite and the unreinforced matrix material CT specimens the crack growth direction was perpendicular to the applied load. The comparison of the FCG behavior for the two materials is shown in $\mathrm{Fig}$ 13. As shown for the $\Delta \mathrm{K}$ range tested, the crack growth rates for the $[90]_{8}$ oriented composite are always considerably higher than those of the unreinforced material. Possible reasons for this type of behavior will be discussed later. 
The FCG data in Fig 13 is shown for both the heat treated and as-received conditions. For the limited number of tests conducted, there appears to be no appreciable effect of heat treatment on the FCG behavior of the unreinforced material. However, in the [90]8 composite the heat treated material exhibits higher FCG rates in at least the high $\Delta \mathrm{K}$ region.

There were many similarities between the FCG processes observed for the $[90]_{8}$ CT specimens and those already described for the $[0]_{8}$ CT specimens. For the $[90]_{8}$ oriented composite, as in the $[0]_{8}$, the crack initiation occurred mostly in the fiber/matrix interface regions of fibers damaged by the machining process. Figure 14 shows a notch area where the fibers have pulled away from the matrix, leaving in its wake portions of the carbon coating. This indicates that crack growth was accompanied by the cracking of the carbon coating. In a manner very similar to the [0]8 oriented material, crack growth occurred preferentially in the interface region, followed by growth into the matrix ligaments (Fig 15). Again, the matrix deformed mainly by striation forming mechanisms and slippage. In the final stages of cracking, the same mechanisms of debonding and matrix tearing were observed as in the [0] $]_{8}$ CT specimens. There were no major differences in the failure processes between the heat treated and as-received composite. Discussion

The results obtained in this study pose a number of important questions: 1$)$ Why is the behavior of the [0] $]_{8}$ oriented SEN and CT specimens so radically different?; 2) What is the effective 
driving force for crack growth in the SEN specimens ?; and 3) Why are the fatigue mechanisms of the $[0]_{8}$ and $[90]_{8}$ oriented CT specimens so similar?

As mentioned earlier, the crack growth direction was parallel to the loading direction for the $[0]_{8}$ CT specimens and normal to the loading direction in the $[0]_{8}$ SEN specimens. A comparison of the simple bending and shear stresses at the notch root for the two specimen geometries may explain the difference in behavior. As shown in Fig 16 the bending and shear stresses were respectively 13 and 2 times greater for the CT specimens in comparison to the SEN specimens. These higher bending stresses were able to preferentially crack the interface region and drive the crack front in the direction parallel to the loading direction. In the case of the SEN specimens, the considerably lower bending stresses and somewhat lower shear stresses were inadequate to crack the fiber/matrix interface region. The result was that the crack growth in the SEN specimens was confined to the matrix and bypassed the fibers leaving them unbroken in the crack wake with little evidence of failure in the fiber/matrix interface. As the crack grew longer in the SEN specimens, fiber bridging acted to reduce the bending stresses at the crack tip and thus the crack growth direction remained normal to the loading crack.

Fiber bridging in the SEN specimens reduced the near tip crack displacements which are the driving force for crack extension. As the crack grew longer, more fibers bridged the crack wake. This resulted in a progressive decrease in the fatigue crack growth 
rates and finally lead to full crack arrest (Fig 2). The very efficient transfer of the load from the cracked matrix to the unbroken fibers resulted in no apparent change in compliance as measured by the extensometer mounted in the crack mouth. This points to the inadequacy of the far field measuring devices to characterize the fatigue crack growth behavior of a complex material such as this composite.

The use of the fatigue loading stage inside the SEM allowed precise measurements of the near tip crack opening displacements to be obtained. These measurements were used to estimate the extent of fiber bridging and to calculate the effective driving force in the $[0]_{8}$ SEN specimens. For a given crack length $c$ and distance behind the crack tip $t$, eq (1) can be shown to result in the following:

$$
\Delta \mathrm{u}_{\mathrm{NB}} \propto \Delta \mathrm{K}_{\mathrm{app}}
$$

or for a more general case:

$$
\Delta \mathrm{u} \quad \alpha \Delta \mathrm{K}
$$

Since according to eq. (3) crack tip displacements are proportional to $\Delta K$, and both the bridged and unbridged displacements are known, the following equation for an effective crack driving force can be applied :

$$
\Delta \mathrm{K}_{\mathrm{eff}}=\frac{\Delta \mathrm{u}_{\mathrm{B}} \times \Delta \mathrm{K}_{\mathrm{app}}}{\Delta \mathrm{u}_{\mathrm{NB}}}
$$

In Fig 17 the fatigue crack growth rate data for a SEN specimen is plotted as a function of both the global $\Delta \mathrm{K}_{\mathrm{app}}$ parameter and the calculated $\Delta \mathrm{K}_{\mathrm{eff}}$ parameter. For comparison purposes also 
shown in the figure is the FCG rate data obtained from unreinforced matrix CT specimens. The FCG rates for the [0] 8 SEN specimens decreased as a function of the $\Delta \mathrm{K}_{\mathrm{app}}$. For the $\mathrm{same} \Delta \mathrm{K}_{\mathrm{app}}$, the FCG rates were three orders of magnitude slower for the [0]。 composite than the unreinforced material. This large difference in the measured FCG rates is due almost entirely to the crack bridging experienced by the SEN specimens. Some of the SEN fatigue crack growth data was recalculated in terms of the $\Delta \mathrm{K}_{\text {eff }}$ parameter to account for crack bridging. As shown in Fig 17, the corrected $[0]_{8}$ data is significantly closer to the data trends exhibited by the unreinforced matrix material. For the data points for which the $\Delta \mathrm{K}_{\text {eff }}$ parameter was calculated, the stress intensity shifted from approximately $30 \mathrm{MPa} \sqrt{\mathrm{m}}$ to $6-8 \mathrm{MPa} \sqrt{\mathrm{m}}$. A stress intensity range of 3-4 MPa $/ \mathrm{m}$ produced comparable crack growth rates in the unreinforced matrix material. The remaining difference between the actual FCG rates in the unreinforced matrix material and the FCG rates of the $[0]_{8}$ SEN specimens, measured in terms of $\Delta \mathrm{K}_{e f f}$, may in part be due to environmental effects. The unreinforced matrix material was tested in the ambient environment while the $[0]_{8}$ composite was tested in vacuum. In the low crack growth region ambient environment has been shown to increase the FCG rates of titanium based alloys (7). Also, the COD measurements were obtained on the specimen surface and they may not fully represent crack tip opening displacements through the specimen thickness.

The $\Delta u_{b}$ measurements used to calculate the $\Delta K_{\text {eff }}$ parameter were obtained at an approximate distance of $100 \mu \mathrm{m}$ behind the crack tip. 
In order to check the sensitivity of the calculated $\Delta \mathrm{K}_{\text {eff }}$ parameter to the location of the $\Delta \mathrm{u}_{\mathrm{b}}$ measurements, the $\Delta \mathrm{K}_{\mathrm{eff}}$ parameter was calculated using displacement measurements obtained at various distances behind the crack tip. It was determined that as long as the measurements where within a relatively small distance from the crack tip, the $\Delta K_{\text {eff }}$ parameter remained essentially the same.

The difference between the $\Delta \mathrm{K}_{\mathrm{app}}$ and $\Delta \mathrm{K}_{\mathrm{eff}}$ is the equal to the reduction in the applied stress intensity due to fiber bridging. For these particular SEN tests, the bridging resulted in a decrease of approximately 22-24 MPa $\sqrt{m}$ in the stress intensity range.

There have been many discussions in the past regarding the applicability of linear elastic fracture mechanics to characterize the FCG behavior of composites. However in the case of the $[0]_{8}$ oriented SEN specimens, crack propagation was confined to the isotropic matrix material leaving in its wake unbroken fibers. The presence of the unbroken fibers in the crack wake can be thought of as a highly rigid mechanical constraint acting to reduce the crack tip opening displacement range in the isotropic matrix. Linear elastic fracture mechanics is well suited to describe this type of behavior.

One of the major findings of the study was the close similarity of the fatigue failure processes for the two different composite orientations tested using CT specimen geometry (compare Figs 12 and 15). The most important event which lead to this similarity in the fatigue behavior was the preferential cracking 
of the interface region, in particular the carbon coatings surrounding the fibers. The cracking of the interface region occurred for both CT orientations tested, and promoted confinement of the crack growth to the fiber direction. While crack growth in the fiber direction is not surprising in the [90] 8 oriented CT specimens, it is somewhat surprising in the [0] $]_{8}$ CT specimens. For the [90 $]_{8}$ specimens, cracking of the weak interface region normal to the applied tensile load apparently occurred first. These microcracks later propagated into the matrix and linked together resulting in a dominant crack growing in the fiber direction. For the $[0]_{8}$ CT specimens, with the main crack growing in the direction of the applied load, one would expect the shear stresses to control the FCG behavior. However, calculations of the shear and bending stresses shown in Table II, reveal that the bending stress $\sigma_{x x}$ perpendicular to the fiber direction, is initially twice that of the shear stress $\tau_{x y}$ parallel to the fibers, with the ratio increasing as the crack grows further in the fiber direction. These relatively high bending stresses must have been high enough to initiate cracking of the interface region perpendicular to the $\sigma_{x x}$ direction. The cracking in the interface region was followed by propagation and linkage of the cracks in the matrix ligaments. The relatively high shear stresses in the $[0]_{8}$ CT specimens might have further contributed to keeping the crack front in the fiber direction by weakening the fiber/matrix interface. However, from the fractographic evidence as well as the above mentioned analysis, it is evident that the tensile loads perpendicular to the fiber 
direction played the major role in controlling the FCG behavior of the CT $[0]_{\theta}$ specimens by preferentially cracking the interface region.

A schematic illustration of the crack initiation and propagation processes discussed above, for both composite orientations, is proposed and shown in Fig 18. The process can be summarized as follows: 1) cracking of the interface region perpendicular to the resulting $\sigma_{\mathrm{xx}}$ stresses; 2) local debonding occurring in the failed interface region and growth of microcracks into the matrix; 3) linking of the cracks in the matrix ligaments. This is a continuing process requiring continuous cracking of the interface region layer at or ahead of the crack front.

The FCG rate of the $[90]_{8}$ CT specimens was considerably greater than that of the unreinforced matrix for a given stress intensity tested (Fig 13). The fatigue mechanisms within the matrix region (i.e. formation of striations, slip deformation etc) were very similar for both the $[90]_{8}$ and the unreinforced material and thus probably did not contribute to the observed differences in the FCG rates. However, the ease of cracking of the interface region, in particular the carbon coating, is probably responsible for the increase in the crack growth rates. This is consistent with the hypothesis that the fiber/matrix interface has lower fatigue resistance than the matrix. This weak composite constituent therefore limited the fatigue cracking resistance of the $[90]_{8}$ composite. 
Conclusions

1. Fatigue crack growth behavior of the SCS-6/Ti-15-3 composite is a function of specimen geometry, fiber orientation and the interaction of local stress fields with the highly anisotropic composite.

2. For the $[0]_{8}$ SEN specimens the crack growth was normal to the loading direction while for the $[0]_{8}$ CT specimens crack growth was along the fiber direction parallel to the loading direction. The difference in the fatigue behavior for the two specimen geometries was attributed to the significantly higher bending stresses in the interface region for the CT specimens.

3. Near crack tip opening displacements were measured for the SEN specimens. A formulation that uses both the actual bridged displacements and analytically derived unbridged displacements was proposed to determine the effective stress intensity parameter $\Delta \mathrm{K}_{\mathrm{eff}}$ to account for the effect of bridging on crack driving force. The new parameter accounted for most of the bridging.

4. The fatigue crack growth processes for the CT specimen geometry were controlled by the preferential failure of the fiber/matrix interface for both composite orientations tested. The interface proved to be the composites weakest link. 


\section{References}

1. Telesman, J., Kantzos P., and Brewer D., "Insitu Fatigue Loading Stage Inside Scanning Electron Microscope" in Lewis Structures Technology 1988, NASA CP 3003 Vol.3, 1988, pp 161-172.

2. Rhodes, C.G., and Spurling, R.A., "Fiber-Matrix Reaction Zone Growth Kinetics is SiC-Reinforced Ti-6Al-4V as Studied by Transmission Electron Microscopy" in Recent Advances in Composites in the United States and Japan, ASTM STP-864, J.R. Vinson and M. Taya, eds., ASTM, Philadelphia, 1985, pp. 585-599,.

3. Lerch, B.A., Gabb, T.P., and Mackay, R.A., "A Heat Treatment Study of the SiC/Ti-15-3 Composite System", NASA TP 2970, 1990. 4. Bueckner, H.F., "Weight Functions for the Notched Bar", Z . Angew. Math. Mech., Vol 51, 1971, pp. 97-109.

5. Gabb, T.P, Gayda, J., and Mackay R.A., "Isothermal and Nonisothermal Fatigue Behavior of a Metal Matrix Composite". Journal of Composite Materials, Vol.24, No.6, June 1990, to be published.

6. Johnson, W.S., Lubowinski, S.J., and Highsmith, A.L, "Mechanical Characterization of Unnotched $\mathrm{SCS}_{6} / \mathrm{Ti}-15-3$ Metal Matrix Composite at Room Temperature" in Thermal and Mechanical Behavior of Ceramic and Metal Matrix Composites, eds., Kennedy, Moeller and Johnson, ASTM STP 1080, 1990, to be published.

7. Shih, T.T and Wei, R.P., "Load and Environment Interactions in Fatigue Crack Growth", in Prospects of Fracture Mechanics, eds., G.C. Sih, H.C. van Elst, and D. Broek, Noordhoff, 1974, pp. 231248 . 
TABLE I. - TEST MATRIX

\begin{tabular}{|l|c|c|c|}
\hline \multirow{2}{*}{ Material tested } & \multicolumn{3}{|c|}{ Specimens tested } \\
\cline { 2 - 4 } & R Ratio & As-received & Heat treated \\
\hline CT, [0]8 & 0.1 & 2 & 1 \\
SEN, [0]8 & .5 & 2 & - \\
CT, [90]8 & .1 & 1 & 1 \\
CT, unreinforced & .1 & 1 & - \\
matrix & .5 & 2 & \\
CT, unreinforced & .5 & & \\
matrix & & & \\
\hline
\end{tabular}

TABLE II. - A COMPARISON OF BENDING AND SHEAR STRESSES FOR THE CT, [0]8 SPECIMENS AT INITIATION AND FAILURE

\begin{tabular}{|l|c|c|}
\hline & $\begin{array}{c}\text { Maximum bending } \\
\text { stress, } \\
\text { MPa }\end{array}$ & $\begin{array}{c}\text { Maximum shear } \\
\text { stress, } \\
\text { MPa }\end{array}$ \\
\hline Initiation & 90 & 45 \\
Failure & 220 & 65 \\
\hline
\end{tabular}




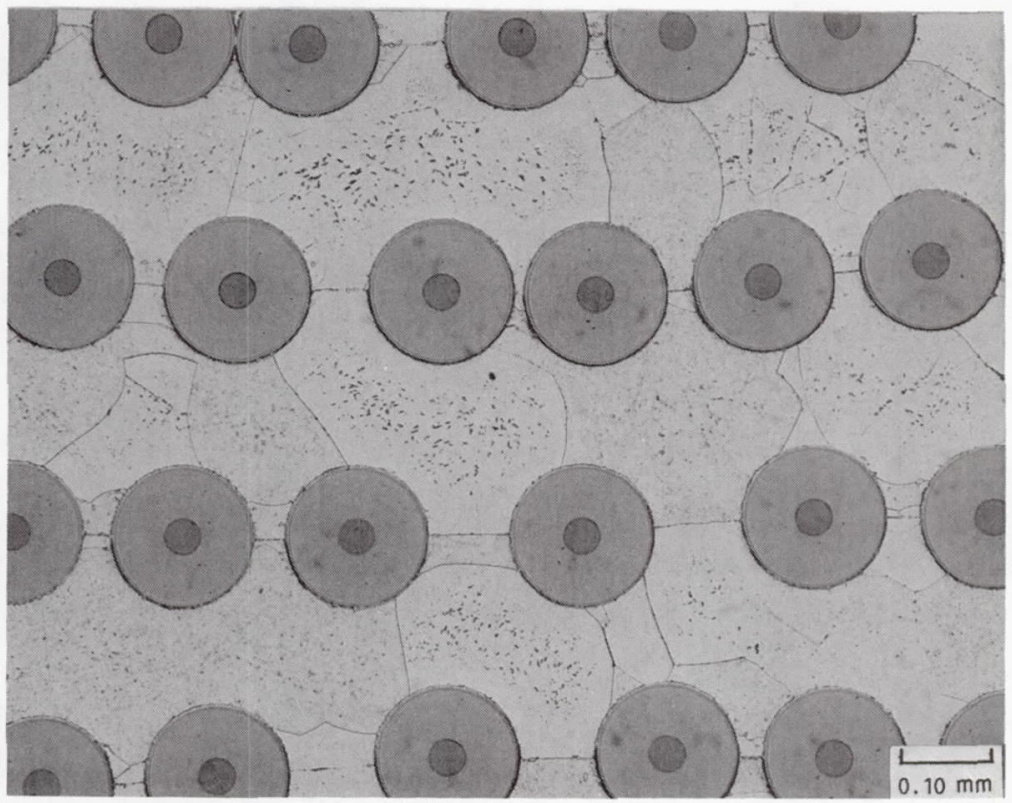

(a) AS RECEIVED-ETCHED TO REVEAL MICROSTRUCTURE.

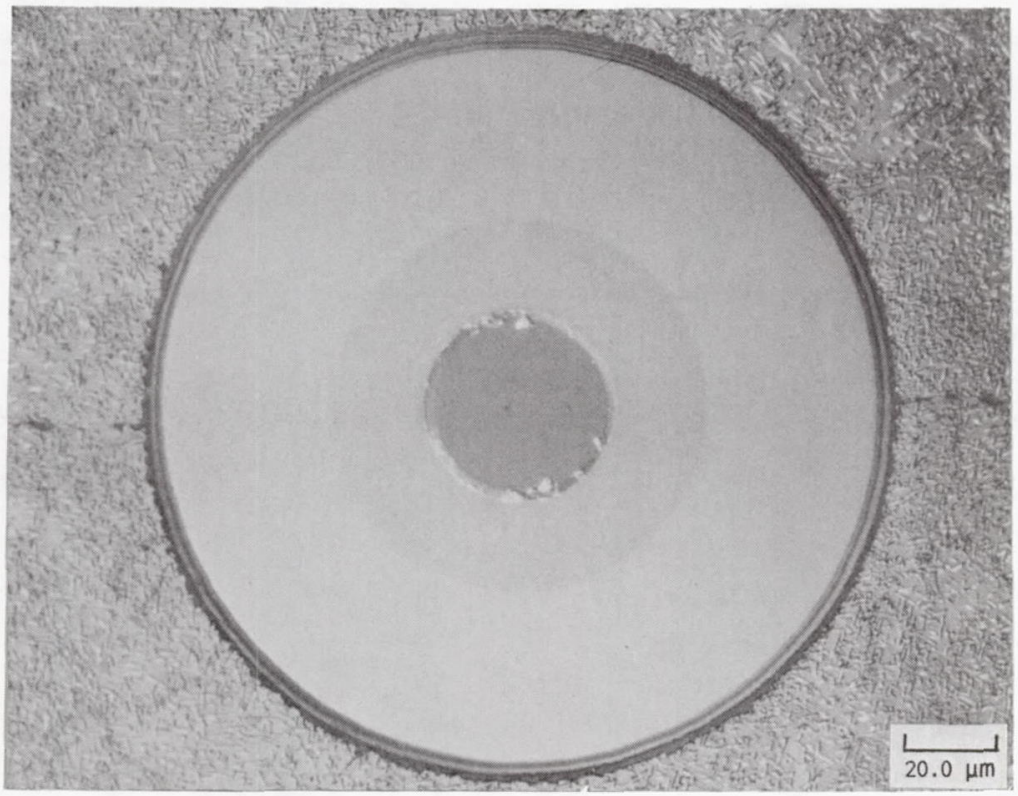

(b) DETAILED VIEW OF SCS-G FIBER-HEAT TREATED.

FIGURE 1. - SCS-6/Ti-15-3 COMPOSITE. 


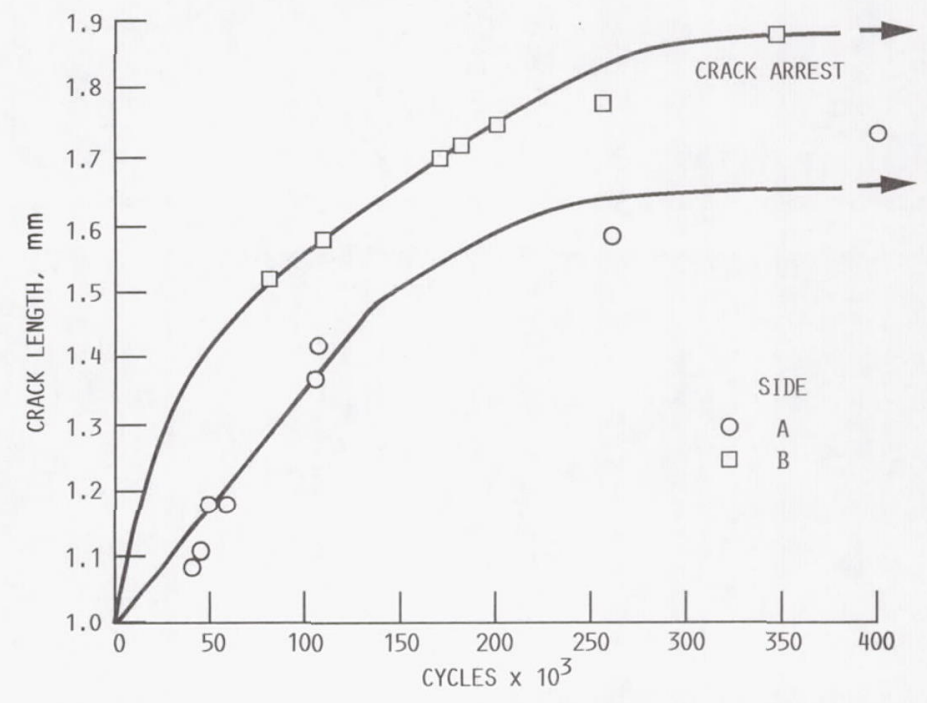

FIGURE 2. - CRACK LENGTH VERSUS CYCLES FOR THE $[0]_{8}$ ORIENTED SEN SPECIMEN.

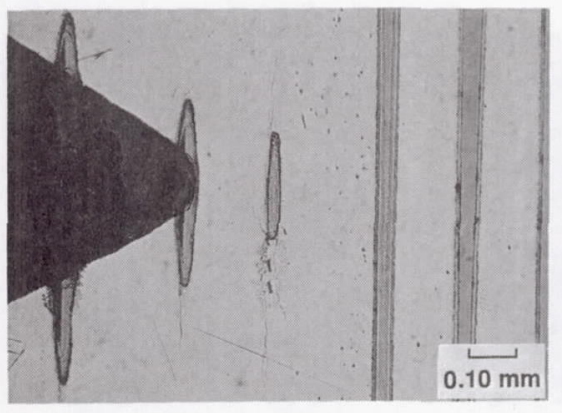

PRIOR TO TESTING

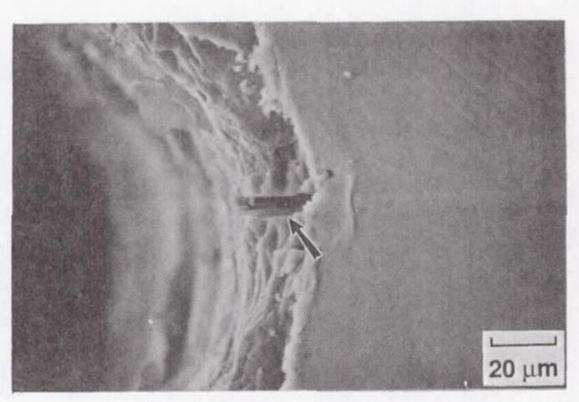

AFTER 150 CYCLES

FIgURE 3. - CRACK INITIATION IN THE $[0]_{8}$ ORIENTED SEN SPECIMEN. 

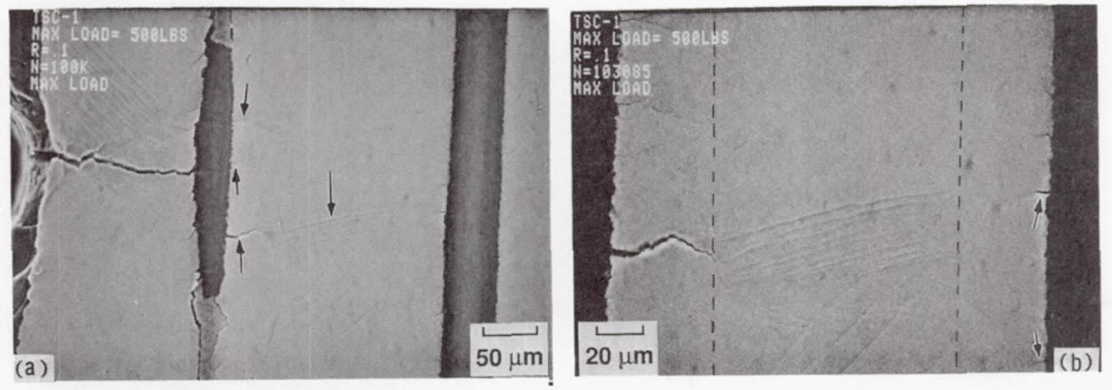

AFTER 100000 CYCLES

MAXIMUM LOAD
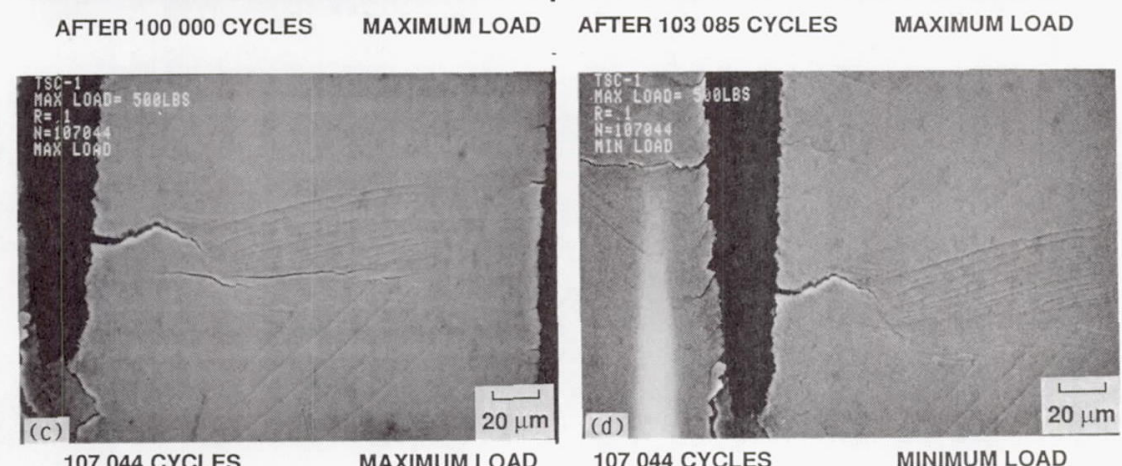

107044 CYCLES

MAXIMUM LOAD

107044 CYCLES

MINIMUM LOAD
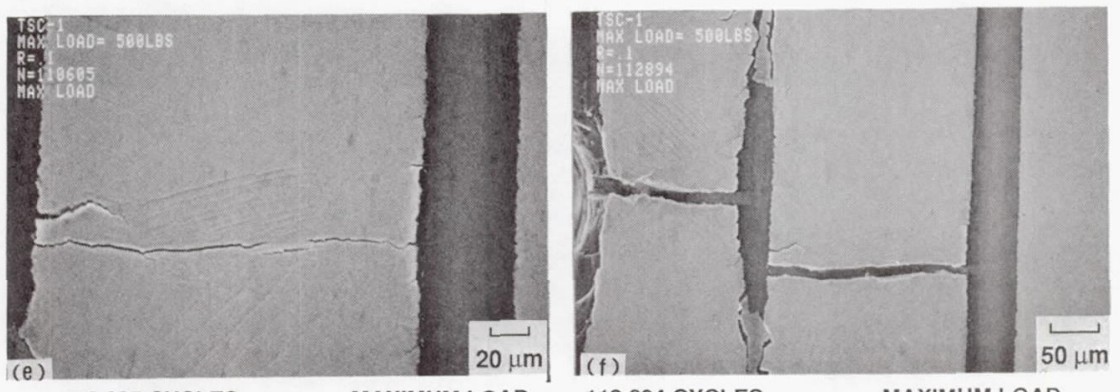

110605 CYCLES

MAXIMUM LOAD

112894 CYCLES

MAXIMUM LOAD

FIGURE 4. - CRACK GROWTH SEQUENCE IN THE $[0]_{8}$ SEN SPECIMEN RESULTING IN FIBER BRIDGING OF THE CRACK WAKE.

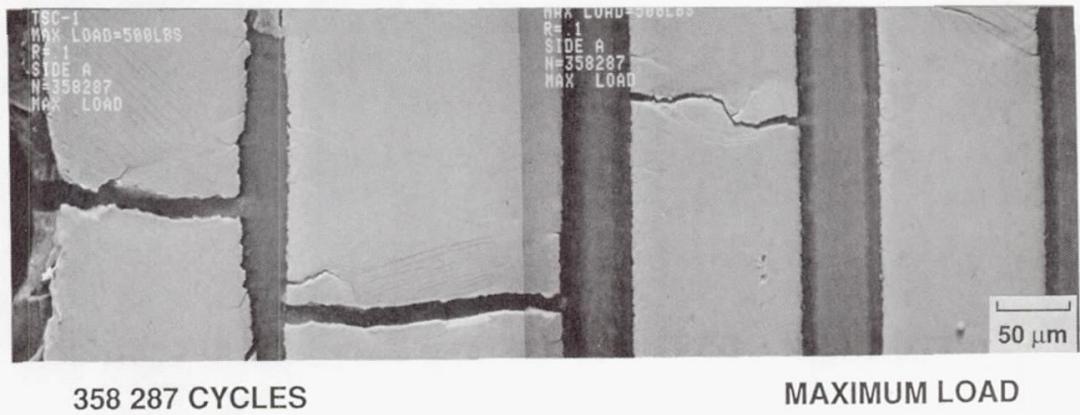

FIGURE 5. - GENERAL APPEARANCE OF THE FATIGUED $[0]_{8}$ SEN SPECIMENS AS OBSERVED IN LOADING STAGE INSIDE AN SEM. 
DISPLACEMENT PROFILE VERSUS DISTANCE FROM CRACK TIP

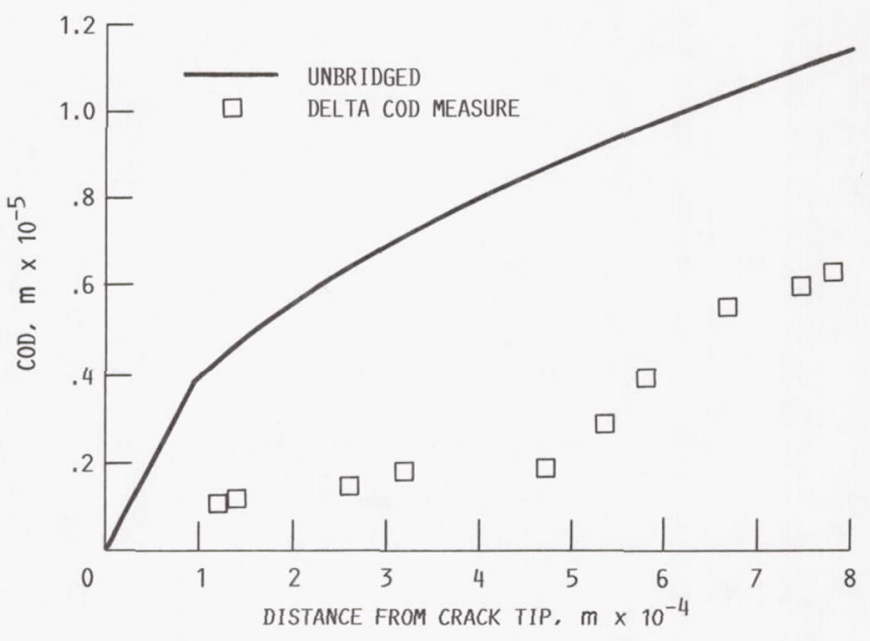

FIGURE 6. - COMPARISON OF THE MEASURED DELTA COD'S WITH ANALYTICALLY CALCULATED COD'S FOR AN UNBRIDGED SEN SPECIMEN.

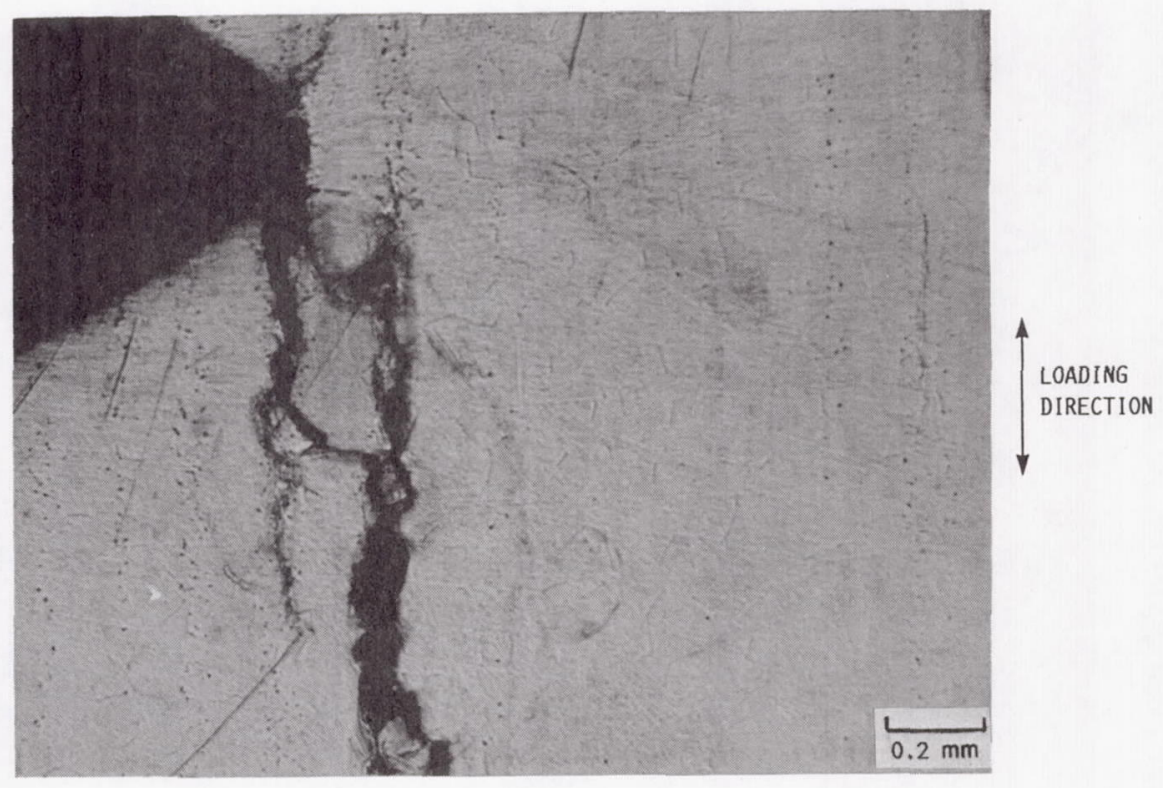

${ }^{[0]_{8}}$ ORIENTATION.

FIGURE 7. - CRACK GROWTH PARALlel tO THE LOADING DiRECTION FOR THE CT $[0]_{8}$ ORIENTATION. 


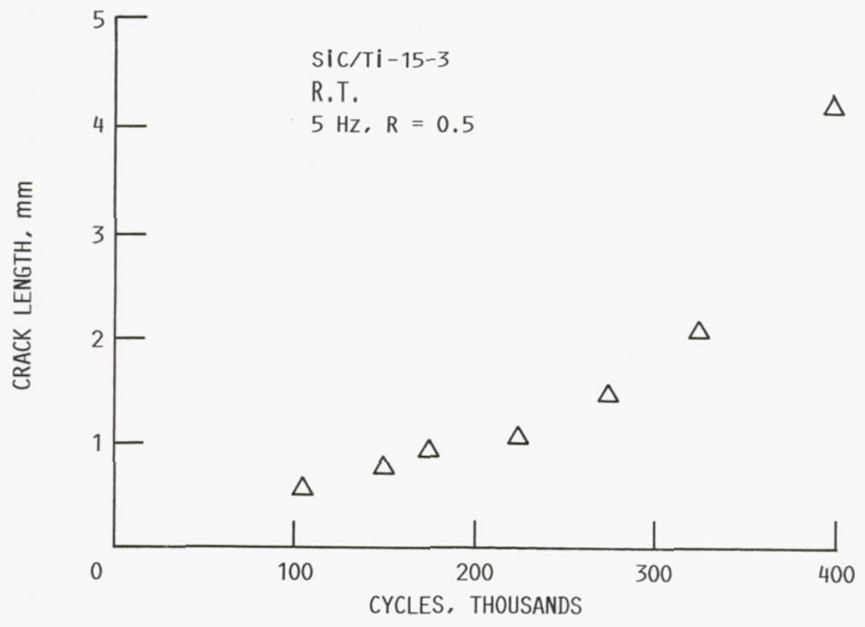

(a) CRACK LENGTH VERSUS CYCLES.

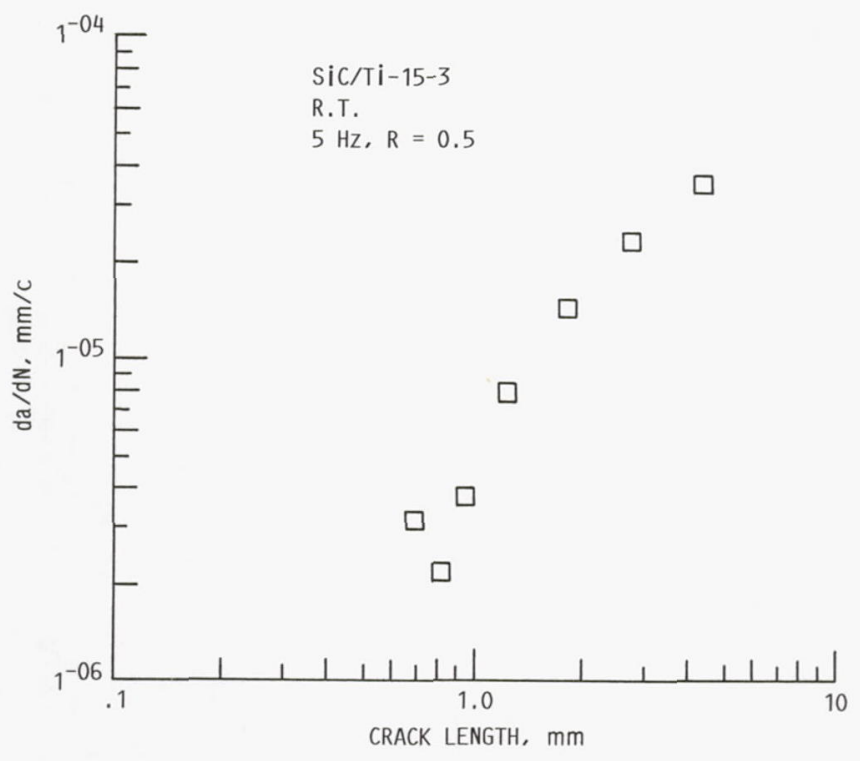

(b) CRACK GROWTH RATE VERSUS CRACK LENGTH.

FIGURE 8. - FATIGUE CRACK GROWTH RATE DATA FOR CT $[0]_{8}$ SPECIMENS. 


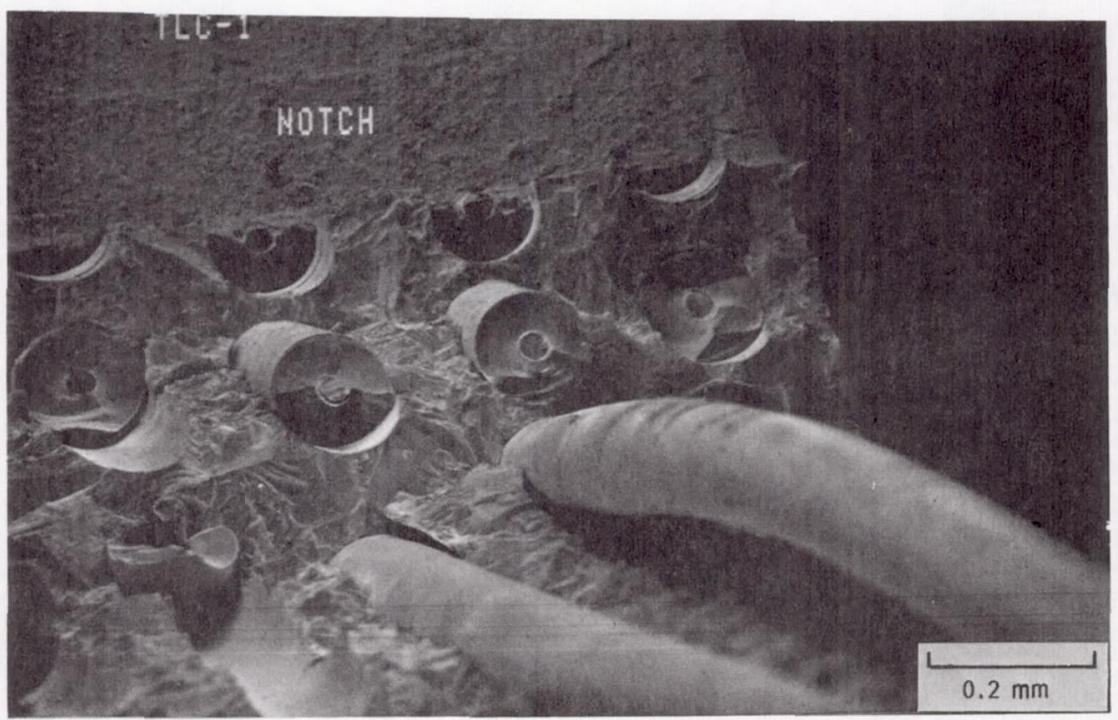

FIGURE 9. - CRACK GROWTH IN THE $[0]_{8}$ CT SPECIMEN. DIRECTION OF LOADING PARALLEL TO FIBER DIRECTION. 

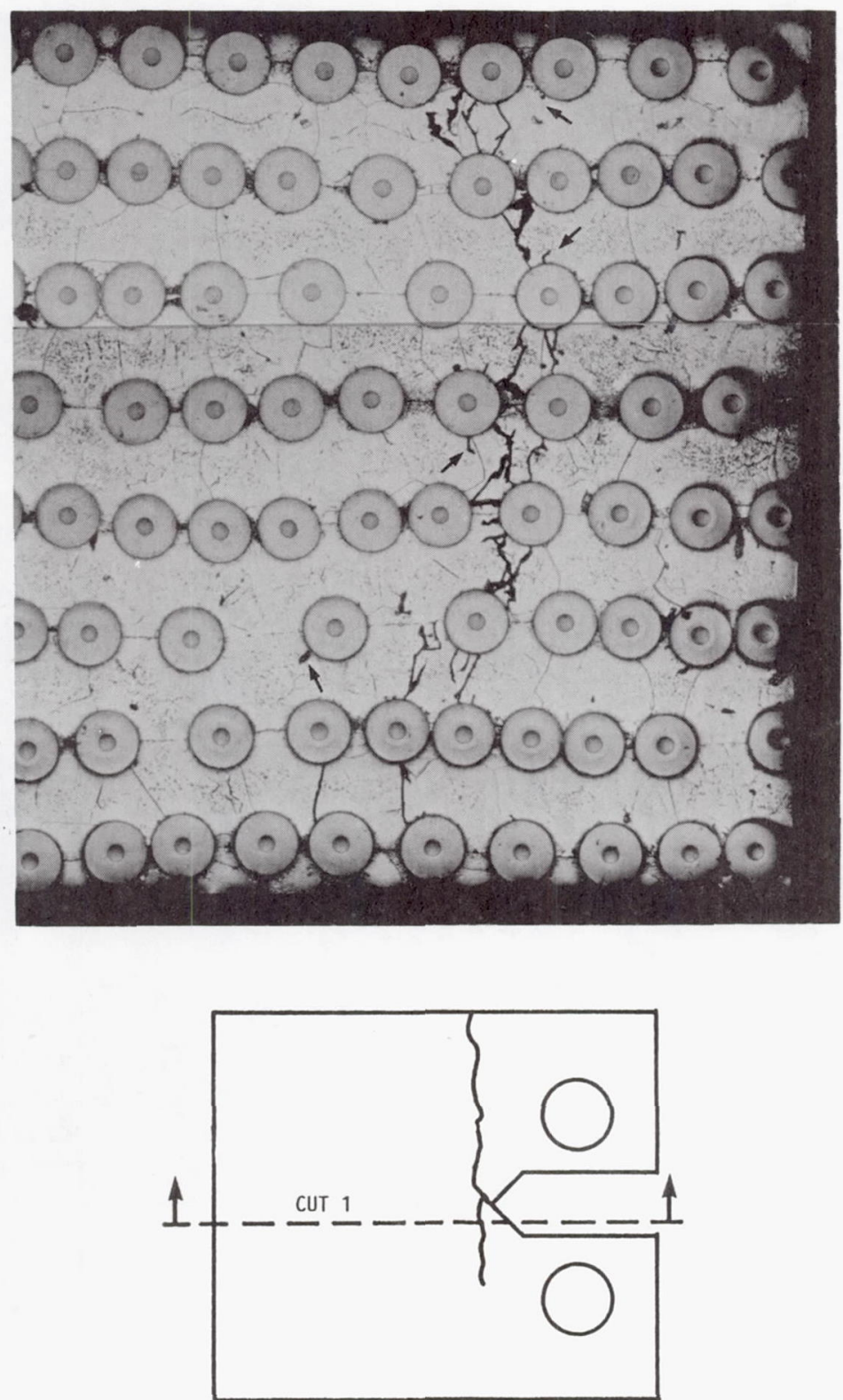

FIGURE 10. - MULTIPLE CRACK INITIATION AND COALESCENCE IN THE EARLY STAGES OF FATIGUE LIFE IN THE CT $[0]_{8}$ COMPOSITE. ARROWS MARK CRACKS INITIATING IN THE INTERFACE REGION. 


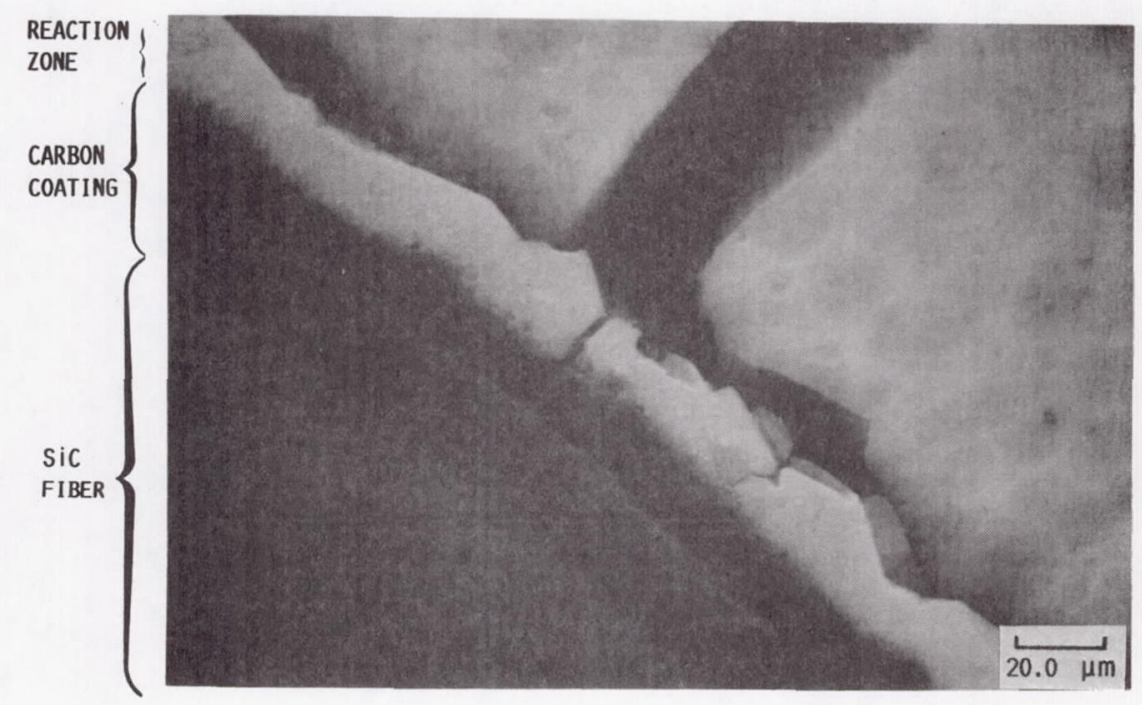

(a) CRACKING EMANATING FROM THE CARBON LAYER.

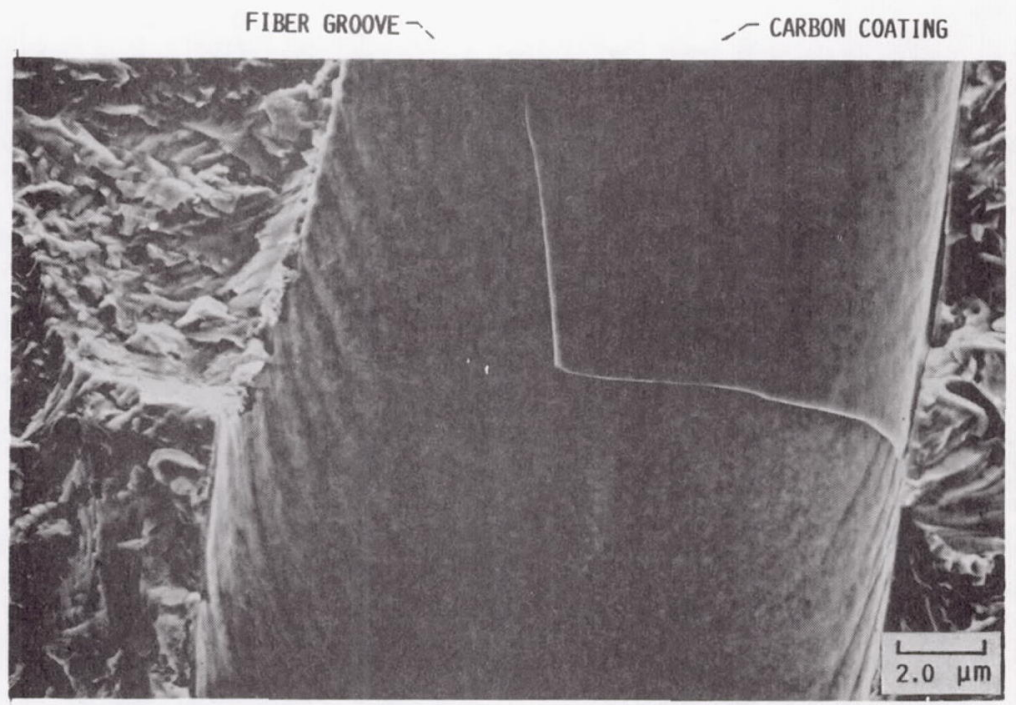

(b) CARBON LAYER SEPARATED FROM THE FIBER DURING FATIGUE.

FIgURE 11. - PREFERENTIAL CRACKING OF THE CARBON LAYER. 
MICROSCOPIC GROWTH DIRECTION

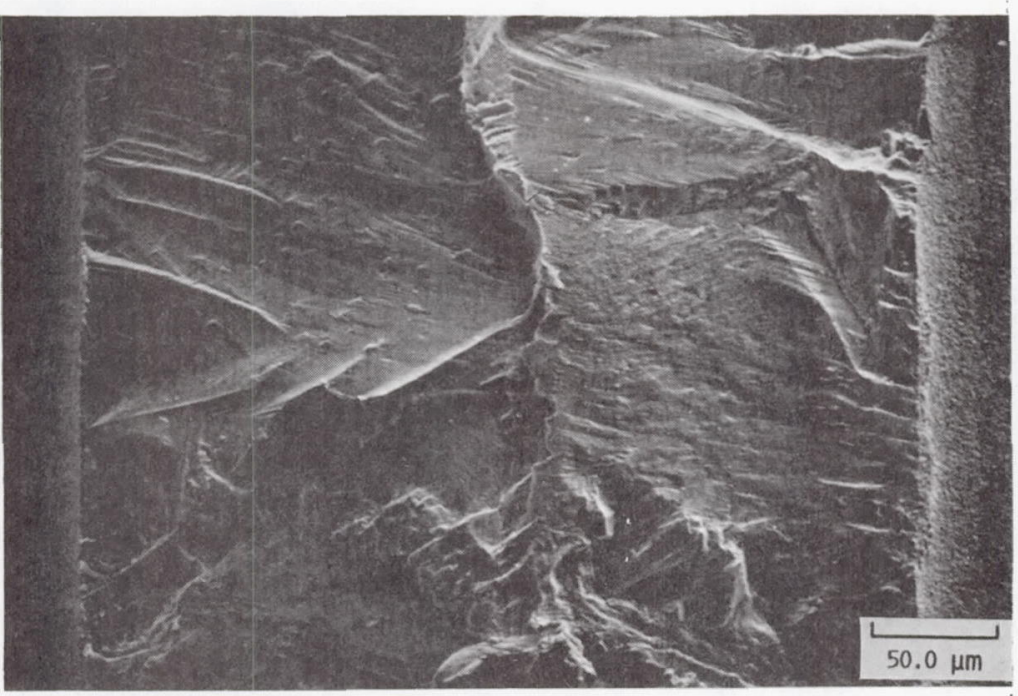

(a) LOW da/dN $[0]_{8}$.

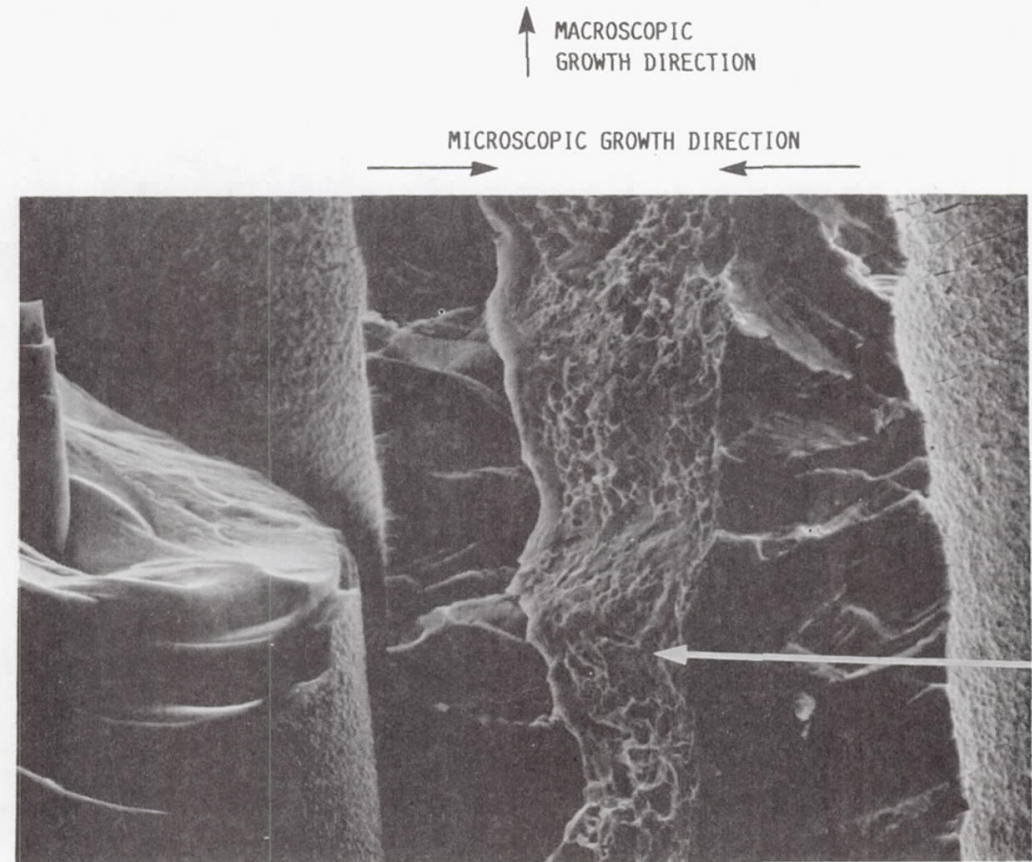

(b) $\mathrm{HIGH} d a / d \mathrm{~N}[0]_{8}$.

FIGURE 12. - MICROSCOPIC CRACK GROWTH DIRECTION FROM THE INTERFACE INTO THE MATRIX LIGAMENT IN THE $[0]_{8}$ CT SPECIMENS. 


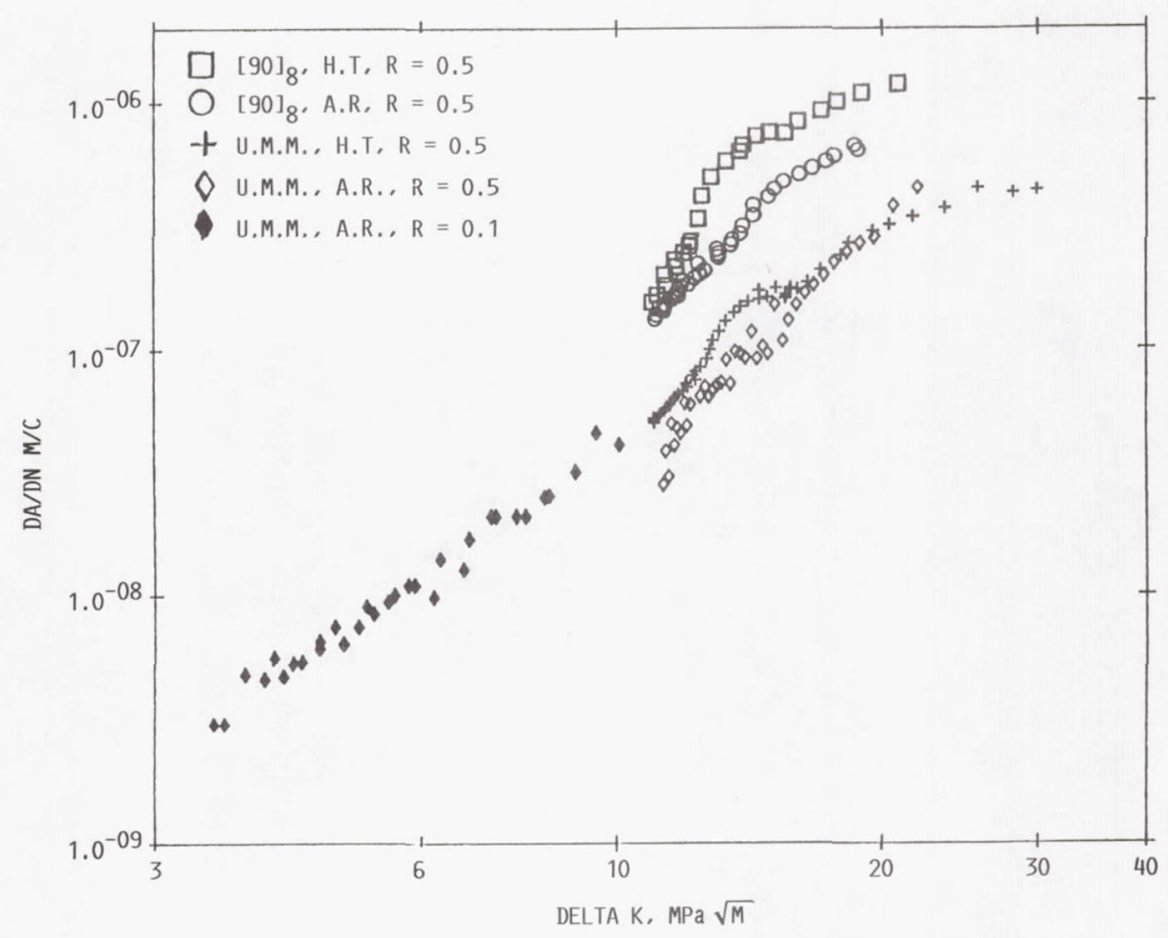

FIGURE 13. - COMPARISON OF FCG RATES FOR THE [90] 8 AND THE UNREINFORCED MATRIX MATERIAL IN THE AS-RECEIVED (A.R.) AND HEAT-TREATED (H.T.) CONDITION.

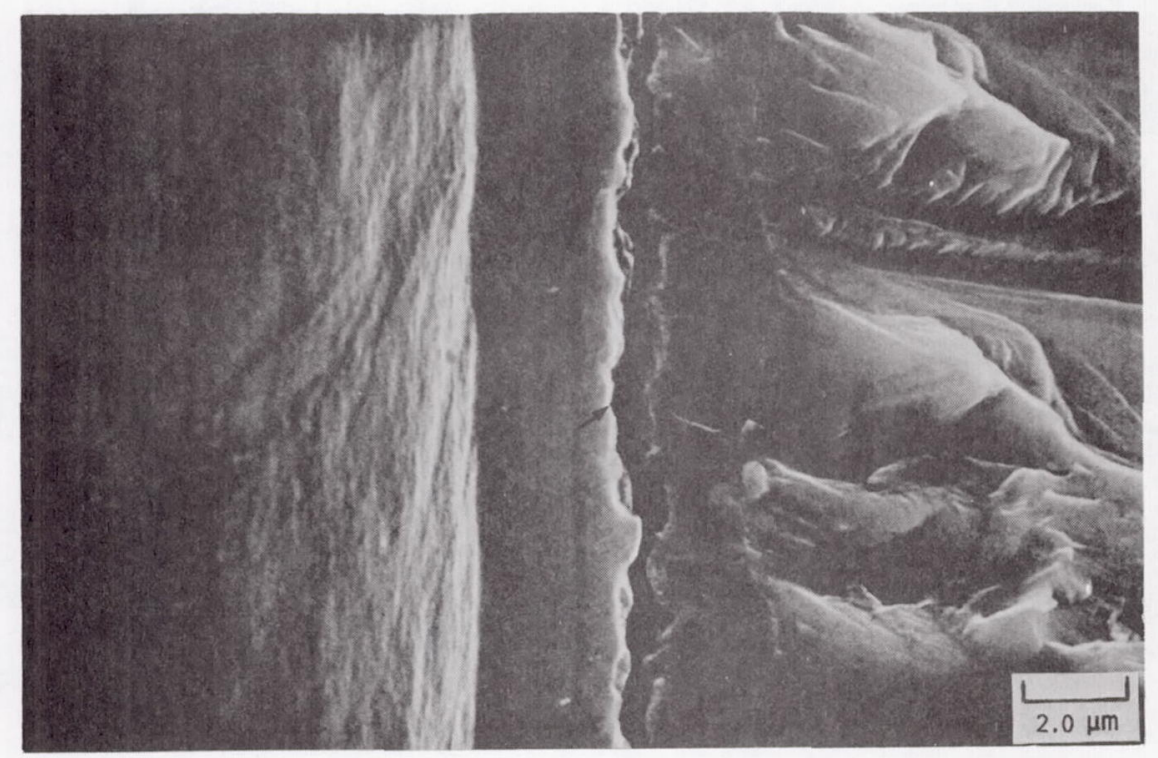

FiguRE 14. - SEPARATION OF CARBON COATING FROM THE FIBER IN [90] 8 CT SPECIMEN. IN THE CENTER OF THE FRACTOGRAPH NOTE A CRACK BETHEEN CARBON COATING AND THE INTERFACE. 


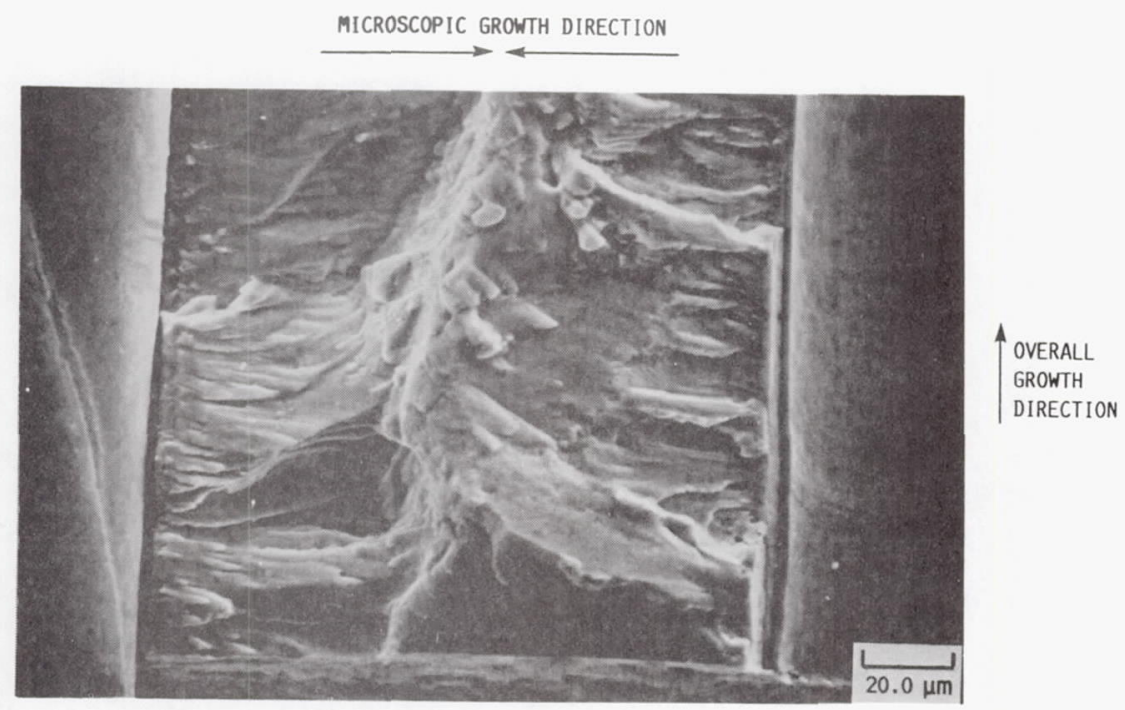

(a) LOW da/dN.

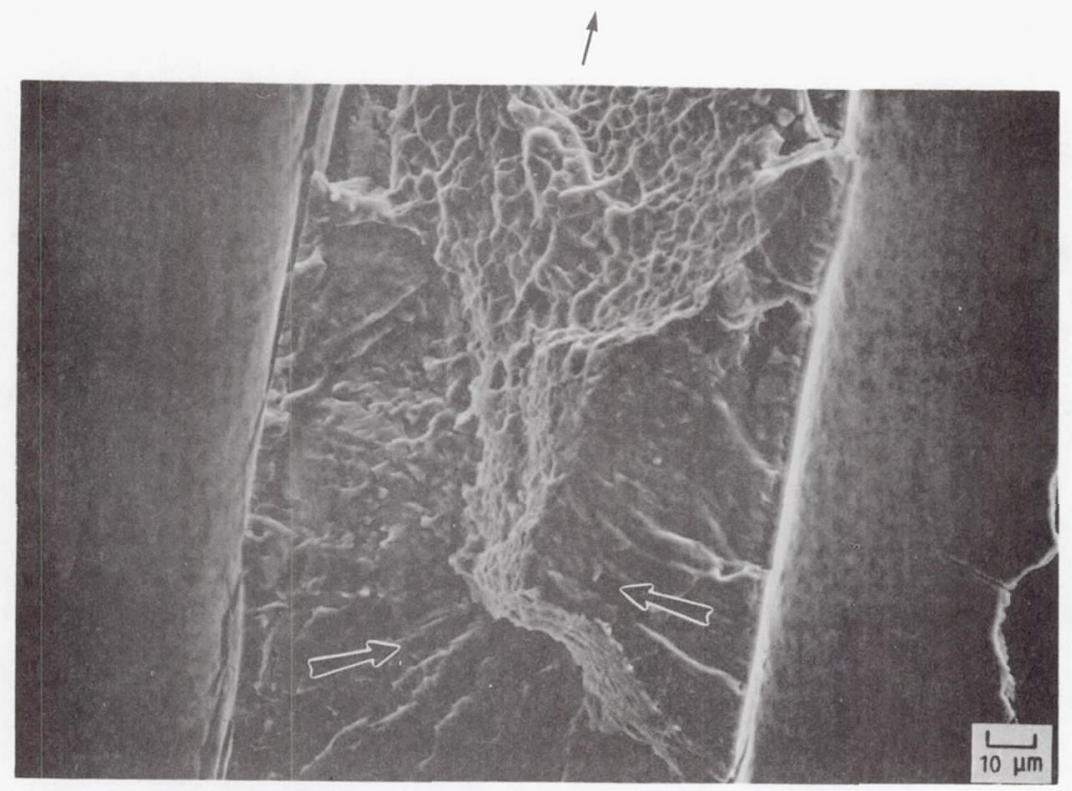

(b) $\mathrm{HIGH} \mathrm{da} / \mathrm{dN}$.

FIGIJRE 15. - MICROSCOPIC CRACK GROWTH FROM THE INTERFACE INTO THE MATRIX LIGAMENTS IN THE $[90]_{8}$ SPECIMENS. 


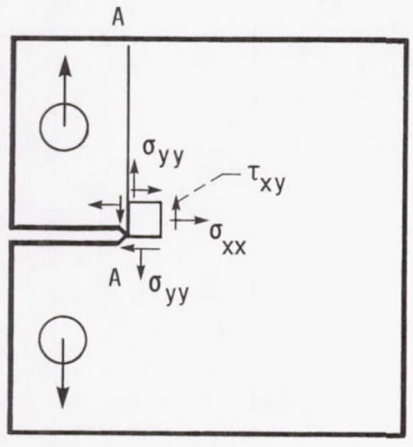

CT SPECIMEN

INITIAL $\mathrm{K}=18 \mathrm{MPa} \sqrt{\mathrm{m}}$

MAX BENDING STRESS $\sigma_{x X}=90 \mathrm{MPa}$

SHEAR STRESS $\quad \tau_{x y}=45 \mathrm{MPa}$

* cracking parallel t0 the lOADING AXIS
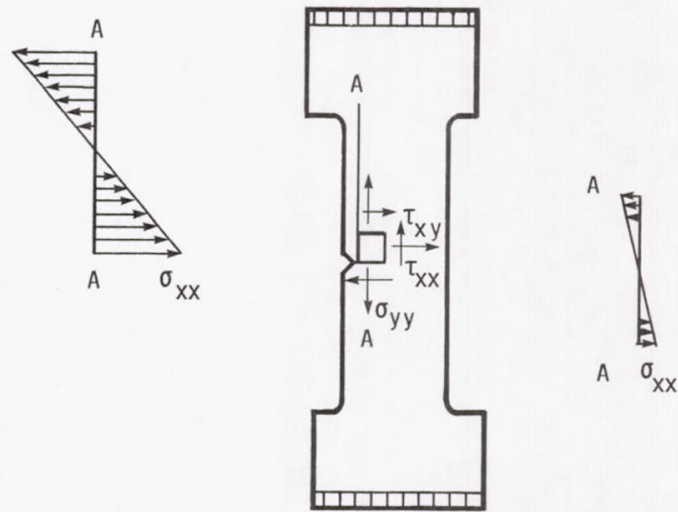

SEN SPECIMEN

INITIAL $K=18 \mathrm{MPa} \sqrt{\mathrm{m}}$

MAX BENDING STRESS $\sigma_{X X}=7 \mathrm{MPa}$

SHEAR STRESS $\quad \tau_{X X}^{X X}=23 \mathrm{MPa}$

* cracking normal to the loadING AXIS

FIGURE 16. - COMPARISON OF BENDING AND SHEAR STRESSES FOR THE TWO SPECIMEN GEOMETRIES.

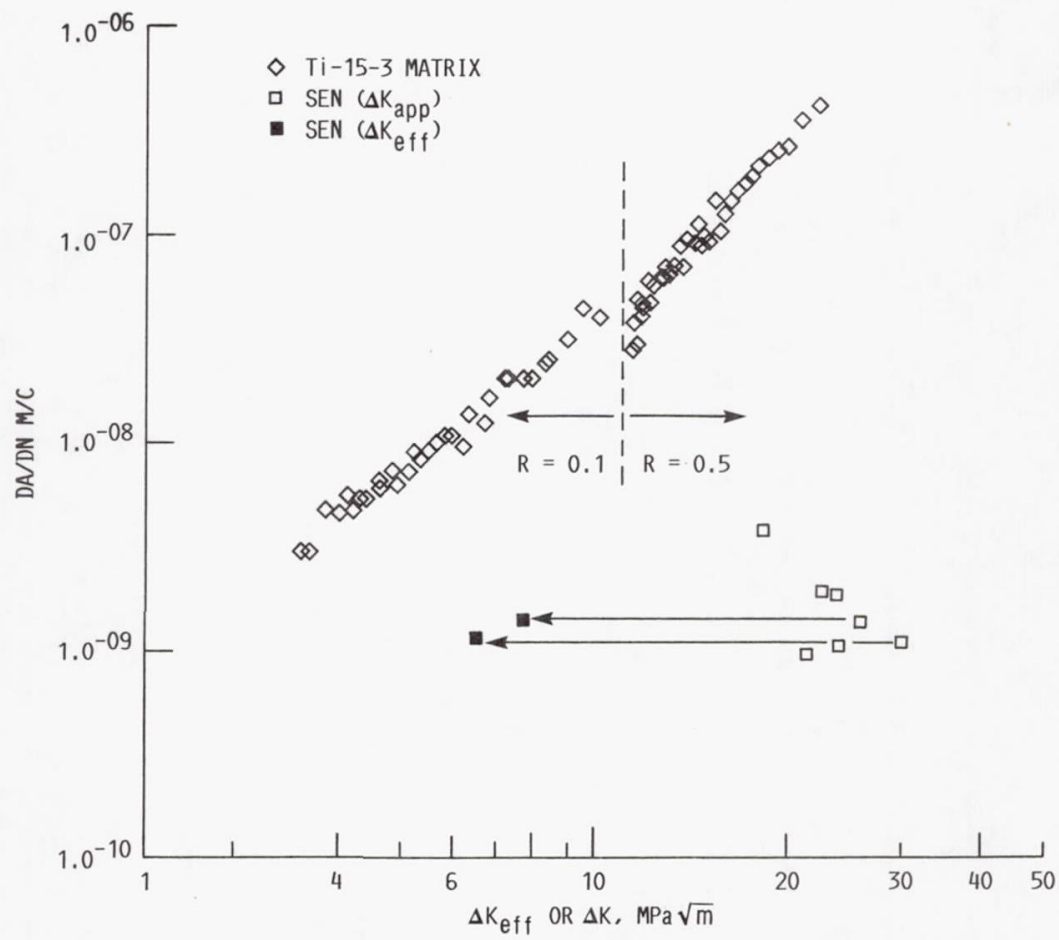

FIGURE 17. - SEN CRACK GROWTH DATA COMPARED TO UNREINFORCE MATRIX MATERIAL IN TERMS OF $\Delta K_{\text {app }}$ AND THE PROPOSED $\Delta K_{\text {eff }}$ PARAMETER. 


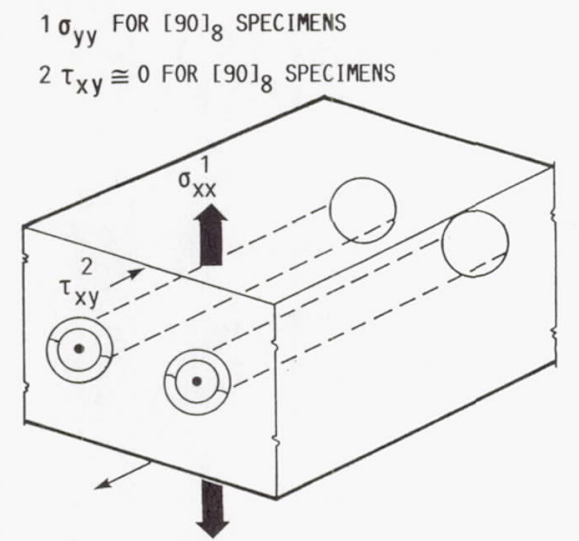

(a) CRACK INITIATION IN THE INTERFACE.

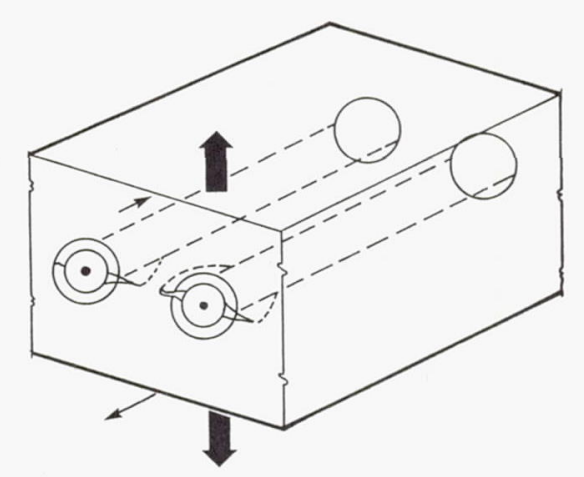

(b) CRACK GROWTH AND LOCAL DEBONDING.

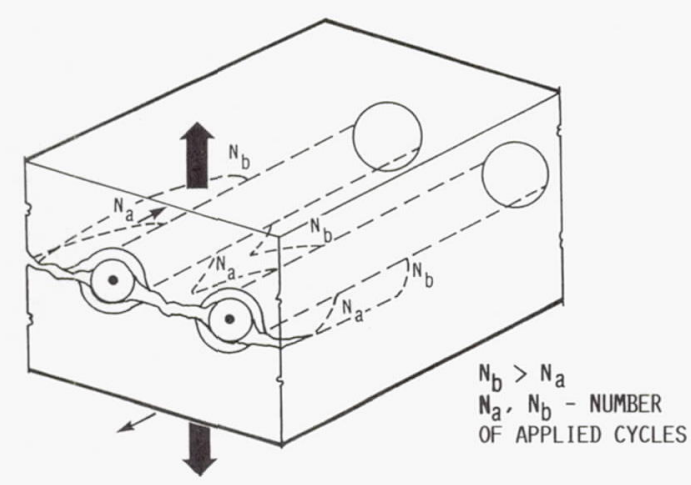

(c) CRACK COALESCENCE IN THE MATRIX.

FIGURE 18. - PROPOSED CRACK INITIATION AND CRACK PROPAGATION PROCESSES FOR THE CT SPECIMEN GEOMETRY. 


\begin{tabular}{l|l|c|}
$\begin{array}{l}\text { 1. Report No. } \\
\text { NASA TM-103095 }\end{array}$ & 2. Government Accession No. & 3. \\
\hline
\end{tabular}

4. Title and Subtitle

Fatigue Crack Growth in a Unidirectional SCS-6/Ti-15-3 Composite

5. Report Date

\begin{tabular}{l|l}
\cline { 3 - 3 } & 6. Performing Organization Code
\end{tabular}

7. Author(s)

Peter Kantzos, Jack Telesman, and Louis Ghosn

8. Performing Organization Report No.

E-5413

10. Work Unit No.

510-01-01

9. Performing Organization Name and Address

National Aeronautics and Space Administration

Lewis Research Center

Cleveland, Ohio 44135-3191

11. Contract or Grant No.

13. Type of Report and Period Covered

Technical Memorandum

12. Sponsoring Agency Name and Address

National Aeronautics and Space Administration

Washington, D.C. 20546-0001

14. Sponsoring Agency Code

15. Supplementary Notes

Prepared for the Third Symposium on Composite Materials: Fatigue and Fracture sponsored by the American Society for Testing Materials, Orlando, Florida, November 6-9. 1989. Peter Kantzos and Jack Telesman, NASA Lewis Research Center. Louis Ghosn, Sverdrup Technology, Inc., NASA Lewis Research Center Group, Cleveland, Ohio 44135 .

\section{Abstract}

An investigation was conducted to characterize and model the fatigue crack growth (FCG) behavior of a SCS-6/Ti-15-3 metal matrix composite. Part of the study was conducted using a fatigue loading stage mounted inside a scanning electron microscope (SEM). This unique facility allowed high magnification viewing of the composite fatigue processes and measurement of the near crack tip displacements. The unidirectional composite was tested in the $[0]_{8}$ (i.e., longitudinal) and $[90]_{8}$ (i.e., transverse) orientations. For comparison purposes unreinforced matrix material produced by the identical process as the reinforced material was also tested. The results of the study reveal that the fatigue crack growth behavior of the composite is a function of specimen geometry, fiber orientation and the interaction of local stress fields with the highly anisotropic composite. In the case of $[0]_{8}$ oriented single edge notch (SEN) specimens and $[90]_{8}$ oriented compact tension (CT) specimens, the crack growth was normal to the loading direction. However, for the $[0]_{8} \mathrm{CT}$ specimens the crack grew mostly parallel to the loading and the fiber direction. The unusual fatigue behavior of the $[0]_{8} \mathrm{CT}$ specimens was attributed to the specimen geometry and the associated high tensile bending stresses perpendicular to the fiber direction. These stresses resulted in preferential cracking in the weak interface region perpendicular to the fiber direction. The interface region, and in particular the carbon coating surrounding the fiber proved to be the composites weakest link. In the $[0]_{8}$ SEN the crack growth was confined to the matrix leaving behind unbroken fibers which bridged the cracked surfaces. As the crack grew longer, more fibers bridged the crack resulting in a progressive decrease in the crack growth rates and eventual crack arrest. The actual near crack tip displacement measurements were used in a proposed formulation for a bridging-corrected effective crack driving force, $\Delta \mathrm{K}_{\mathrm{eff}}$. This parameter was able to account for most of the experienced bridging and correlated the $[0]_{8}$ SEN fatigue crack growth data reasonably well.

17. Key Words (Suggested by Author(s))

Metal matrix composite

Fatigue crack growth

Crack bridging

Fatigue mechanisms

19. Security Classif. (of this report)

Unclassified

20. Security Classif. (of this page)

Unclassified

21. No. of pages 